\title{
THE URINARY EXCRETION OF NOVAR- SENOBILLON IN SYPHILIS AND ITS RELATION TO TOXIC EFFECTS
}

\author{
By Mr. V. E. LLOYD AND DR. N. L. LLOYD
}

Discussion. November 29Th, I929

Dr. David Watson said he was present to-night because of the importance of the subject which these two papers dealt with. He had listened to them with very great pleasure, not only because the subject dealt with in them was of such practical importance, and so demanded attention, but any test which would decrease the risk incidental to the use of salvarsan and similar injections was to be welcomed. This test now submitted seemed to be the simplest so far advanced.

The papers were difficult to criticise, as the writers had themselves done the criticising as they went along. The contributions had been prepared in a very scientific manner, a manner which might well be advantageously copied. He cordially thanked them for the papers, and for their promise to send him details of the test so that he could bring it into use in his work at the earliest date.

Colonel HARRISON said: I should like to congratulate the readers of the paper on its excellence and on the scientific manner in which they have carried out their investigations. I should like also to thank them for focusing attention on a test which may easily be of great value in avoiding the toxic effects of arsenobenzene injections. It occurred to me whilst the paper was being read that possibly the reason for the delayed excretion of the amino-benzene radicle was that it had been seized upon by the liver cells. As you, Sir, will remember, when we served on the Salvarsan Committee a number of years ago, I used to say that we should not speak of arsenical jaundice, but of arsenobenzene, underlining the last syllable. This idea was strongly supported by the likeness of these cases in many respects to poisoning by trinitrotoluene and by the histological examination of 


\section{URINARY EXCRETION OF NOVARSENOBILLON}

the liver by Professor Turnbull at the London Hospital. If this supposition is correct, it may be that we have in the Abelin test a means by which we can rapidly determine the value of any measures we may take to avoid the amino-benzene group being taken up by the liver cells. For example, in the clinic at St. Thomas's Hospital, we have tried previous administration of glucose, and we might find that patients who have been treated in this way may show by the Abelin test a more rapid excretion than do patients treated without any such precaution. Everybody realises the importance of the subject, considering the great anxiety felt by those who have to treat syphilis with arsenobenzene compounds over the question of toxic effects such as jaundice and dermatitis, and I should like again to thank the readers of the paper for the pleasure which it has given me.

Dr. H. C. Semon added his meed of praise as to the excellence of these papers, and congratulated the authors on their self-critical methods. He had never seen toxic jaundice or exfoliative dermatitis ensue on the oral administration of arsenic. An overdose, or an uncontrolled and prolonged medication with the drug had quite different sequelæ, among which neuritis or pigmentation of characteristic type associated in the chronic cases with a more or less generalised anidrosis and dystrophy of the epidermis had been frequently observed. Conversely, these were practically unknown as a complication of salvarsan injections. Considered together, these facts pointed to the amino rather than the arsenical radical as the causative factor in the production of the well-recognised and all too frequent toxic manifestations.

Colonel E. T. BURKE wished to associate himself with those who were congratulating the authors on their papers, which were of extraordinary interest and practical value.

It appeared that the reaction they described demonstrated the presence of an aromatic amino group, and that it had no real association with the presence of arsenic; it had only relation to the molecular structure of the substance administered. As the authors stated, phenacetin gave a positive reaction, and that was probably due to the fact that it contained a substance belonging to that aromatic amino group. The salicylates gave no reaction owing to the absence of the group mentioned. 


\section{BRITISH JOURNAL OF VENEREAL DISEASES}

Practically, the test meant that during the administration of arsenobenzene the presence of the Abelin reaction showed that the kidneys were excreting arsenobenzol; that was so even though, as the authors said, it was not specific. It, therefore, had a value in the treatment of syphilis. It was possible to judge by the intensity of the reaction and its duration what was the efficiency of the kidney. Drs. Lloyd had shown that bad excretors were especially liable to toxic effects when arsenobenzol was administered; there was delay in excretion, with the result that an abnormal amount of arsenobenzene was retained in the body. After listening to these two papers he had reflected that it would be an excellent routine to observe in clinics that even where the kidneys were apparently normal to ordinary tests, to perform a series of Abelin tests on every patient after his first few injections, as it might very well be that the renal excretory function might be abnormal only in respect of arsenobenzene, being normal to other things. Carrying out this test would be a way to find out whether the kidneys would excrete arsenobenzol in a satisfactory way.

He was much interested in what the authors said about jaundice. In his own clinic he saw very little jaundice. He attributed the small amount of jaundice he saw to two facts: (I) that he used stabilarsan as a routine, and he thought that, since in that preparation the arsenobenzene is dissolved in an isotonic glucose solution, the glucose acted as a barrier against toxicity ; (2) he gave arsenobenzene and bismuth not concurrently, but in alternating series. Still, he had recently seen several cases of jaundice, and one result of listening to these papers was that he would now investigate the renal function of such patients by the Abelin test. It might be that the few cases of jaundice which he got could be attributed to hepatic damage as a secondary effect of failure on the part of the kidneys to excrete arsenobenzene. Bismuth jaundice was supposed to be rare; but he had been finding many cases of bismuth jaundice in patients who had not had any arsenobenzol at all. $\mathrm{He}$ very rarely saw jaundice during the arsenobenzene course, but commonly during the bismuth course. Those who had been giving arsenobenzene and bismuth concurrently attributed the jaundice, too often, to arsenobenzene, whereas most of it, in his experience, was due to 
the bismuth itself. It occurred with all the bismuth preparations. A point he would like to see elucidated was the following: What proportion of the intravenous dose was therapeutically utilised? Was the arsenobenzene excreted by the kidneys all waste? Had it been utilised in killing the syphilitic organism ? As far as Levaditi's experiments showed, arsenobenzol did not exert a direct lethal effect on the organism. If an idea could be obtained as to what the ideal dose was, so that the preponderating, or the whole, amount of the drug injected would be utilised in killing the treponemata, then that would be a great advance, and would tend towards reducing the incidence of toxic effects. It is clear that only a portion of the drugs injected are, owing to the rapidity of elimination, able to exert a curative effect; and that that which is excreted unchanged is so much waste. It is dangerous waste, too, for it is this proportion which gives rise to toxicity. Is there a dosage in which all the drug is retained in the body and made therapeutically effective, and in which elimination of the active drug only occurs when this dose is exceeded ? The papers just read were, he thought, a contribution towards elucidating this important question of the ideal dosage.

Dr. H. M. Hanschell also wished to thank the authors for these papers, which had instructed him, for the safety of his patients. In the slow excretors, was it the kidney holding back the benzene ; or was it, as Colonel Harrison suggested, that the benzene did not escape through the kidney because it had been linked up with the liver cells? Clinical observation suggested the latter as the more frequent happening. But the first might occur. For example: Six years ago a patient had given consecutive positive Wassermann tests, and had been admitted to hospital because of kidney disease ; the diagnosis made by his physicians was interstitial nephritis and hyperpyesis. The speaker gave this case $0.3 \mathrm{gm}$. of stabilarsan I.V. The patient died in coma two days later. Since then, however, he had administered novarsenobenzol to syphilitic patients who had another type of disease of the kidney (as indicated by much albuminuria, casts, etc.), with, apparently, clinical benefit to the patients. In the past he had had cases of jaundice following treatment with " 9I4" preparations, but the case with jaundice shown by him that evening was the first in some 2,000 


\section{BRITISH JOURNAL OF VENEREAL DISEASES}

cases who had developed jaundice after treatment with stabilarsan. He had always given stabilarsan and bismuth injections at the same time.

Dr. B. B. ShARP said that he also wondered whether, in the case of bad excretors, the aromatic benzene radicles were rapidly taken up and fixed by the liver, or were retained in the body by deficient excretory power of the kidneys. If what Colonel Harrison suggested was true, that glucose prevented the liver from taking up the benzene radicle, it would be interesting to find out if the administration of glucose improved the excretion in a bad excretor. It would also be well to test the excretory power of the kidneys for other substances when poor excretion of benzene radicles was present.

Dr. D. N. NABARRo said that during the reading of the papers several points had occurred to him in regard to children. He thought the carrying out of this test would be difficult in a children's clinic. Usually the organs of children were in a better working condition than those of older people, and one would therefore expect that toxic symptoms following these injections would be very rare in children. Among many thousands of injections in children he had seen only one case of jaundice, which recovered, and one of exfoliative dermatitis, which proved fatal. The explanation is no doubt due to the fact that children eliminated the drug quickly. He asked whether Mr. Lloyd had examined the urine from the point of view of the renal elements, i.e., as to whether the kidneys were at all affected by the elimination of the drug ?

The points raised by Dr. Sharp were very pertinent.

These papers constituted a very valuable investigation, and would help to determine whether any particular patients were liable to show these toxic manifestations. He would like to ask the authors whether they came upon any cases of delayed excretion of sufficient intensity to justify withholding the treatment, i.e., suggesting that the patient could not take arsenic at all ?

Dr. H. C. SEMON, in further remarks, suggested that any of their hearers who in the future might have the misfortune to meet with a fatal case of toxic jaundice, should immediately provide the authors with a fresh specimen of the liver, and perhaps of some other organsuch as the kidney - as well, in order that their relative response to the Abelin reaction might be investigated. 


\section{URINARY EXCRETION OF NOVARSENOBILLON}

The PRESIDENT said he had been very much interested in these two communications, which reflected great credit on the authors, as they represented the expenditure of much labour, and the results produced were of great value to the Society.

The chemistry of the human body was a very abstruse subject, and much yet remained to be learned about it. With regard to the arsenobenzol compounds, it was known that they were somewhat split up in the body, but it was not known whether any part of the arseno-benzol compound passed through unchanged. Obviously, the test described this evening was one which would show the presence of arsenobenzol compound which might be passed through the body unchanged; but the reaction might also be given by bodies produced by the splitting up of the arsenobenzol compounds in the body into simpler forms so long as these compounds retained the benzene ring with the attached amino-group.

The authors mentioned that they had one or two cases in which the test was entirely negative, and that suggested either a decomposition so complete that there were none of the benzene ring bodies passing through the kidneys, or such a complete absorption in some cells of the body-e.g., in the liver-that, during the period of absorption, none of the compounds passed into the urine, and so did not show their presence by the test. The question of how far the liver cells might hold up these compounds was one of considerable importance, and he agreed with Colonel Harrison's remark that the papers to-night had thrown a distinctly further light upon, or given corroboration of, the suspicions already held as to the cause of jaundice following the use of arsenobenzol compounds.

Dr. Nabarro had referred to the question of the urine, but he, Dr. Coutts, took it for granted that where the observers did not mention the fact the urine was normal before they started the administration of the novarsenobenzol. Perhaps the readers of the papers would reply on those points.

A very valuable feature of the papers was that it had been shown that there was some definite relation between poverty of excretion, as judged by this test, and the liability to toxic results; and that was of very great importance to all concerned in venereal disease work. 


\section{BRITISH JOURNAL OF VENEREAL DISEASES}

From that point of view alone, he was sure members would consider that the evening had been a very valuable one.

Mr. V. E. LLOYD, in reply, said that his brother and he both felt flattered and encouraged by the kind remarks of the President and the various speakers. On most of the questions that arose he hoped that information would have been elucidated during the discussion. Colonel Harrison had discussed the prophylactic value of glucose in protecting the liver cells. He and his brother had not yet attempted to improve poor excretion by using glucose, but they had tried to do so with sodium thiosulphate, in one case, without success.

Colonel Burke was correct in considering that the reaction given by phenacetin was because phenacetin contained a similar aromatic amino group. During their tests they found there were a number of chemical compounds, compounds not used as drugs, which gave positive results with this test. One was para-phenylene diamine, a compound very similar to one of the hair-dyes, and it was conceivable if absorption of this hair-dye took place that the urine would give a positive test. Colonel Burke also discussed the question of bismuth playing a part in the production/of toxic jaundice. Mr. Lloyd regretted that in the paper he had made no reference to bismuth. About one-half of the cases had been treated with bismuth at some time, although three of the five cases of severe toxic jaundice had not had any bismuth ; they were cases of tabes who were not treated with bismuth during the first year. Several speakers were interested in the renal function of these cases. No special renal function tests had been made, but all cases of nephritis and persistent albuminuria had been eliminated from the groups of cases referred to in the papers. 